\title{
DOS ASPECTOS JURÍDICOS DA PEDOFILIA: POR UMA INTERVENÇÃO ESTATAL DIGNA E EFETIVA AO PEDÓFILO
}

\author{
Valéria Silva Galdino Cardin ${ }^{1}$ \\ Caio Eduardo Costa Cazelatto ${ }^{2}$
}

\begin{abstract}
Resumo
A pedofilia é um tema controvertido tanto no âmbito jurídico quanto social. A discussão do pedófilo como um ser doente ou não ainda está distante de um consenso, refletindo diretamente na devida intervenção estatal sobre o assunto. Diante disso, esta pesquisa teve por objetivo analisar, por meio do levantamento bibliográfico, os aspectos conceituais e jurídicos da pedofilia. Para tanto, explorou-se o perfil do pedófilo, apontando este, a partir do viés médico, como um portador de patologia mental, isto é, de uma parafilia. Ainda, elencou-o como um inimputável por ser desprovido da capacidade de autodeterminação de seus atos. Assim, analisou-se uma intervenção estatal digna e eficaz para além da aplicação de uma pena, indicando a medida de segurança como a mais humanística.
\end{abstract}

Palavras-Chave: Castração Química; Direitos de Personalidade; Medida de Segurança; Pedofilia; Pedófilo.

\section{INTRODUÇÃO}

Desde a Grécia Antiga, há relatos de pinturas que retratam pessoas mantendo relações sexuais com crianças. Atualmente, tem-se verificado um aumento no número de casos e de denúncias dessa prática, em decorrência da facilidade que aqueles que são intitulados como pedófilos têm de persuadir suas vítimas, especialmente com o advento da Sociedade da Informação e democratização do uso da internet.

É fato que, ao se estudar a temática, o ponto central, em regra, recai sobre a criança, que é um ser em desenvolvimento físico, psicológico e sexual e que merece especial atenção do Estado e da sociedade. Por outro lado, também é necessário direcionar a atenção ao autor dos abusos sexuais, visando tratá-lo como pessoa, e não como um mero "monstro", desprovido de influências patológicas.

Muito se discute, nos diversos campos do saber, a respeito das condutas pedofilicas serem classificadas como uma parafilia ou como uma mera exteriorização volitiva do pedófilo. Evidentemente, cada ponto de vista

\footnotetext{
${ }^{1}$ Pós-doutora em Direito pela Universidade de Lisboa; Doutora e mestre em Direito das Relações Sociais pela Pontifícia Universidade Católica de São Paulo (PUCSP). Docente da Universidade Estadual de Maringá e no Programa de Pós-graduação em Ciências Jurídicas pelo Centro Universitário de Maringá (UNICESUMAR). Pesquisadora pelo ICETI. E-mail: valeria@galdino.adv.br.

${ }^{2}$ Mestre em Ciências Jurídicas pelo Centro Universitário de Maringá (UNICESUMAR).E-mail: caio.cazelatto@hotmail.com
} 
enseja uma resposta jurídica diferente. Caso for considerada como uma patologia, assim como se buscará esclarecer neste estudo, o Poder Público deverá intervir em conformidade com os institutos do Direito Penal para além da aplicação de uma simples pena.

Neste panorama, a castração química, que é um meio de suprimir a libido humana por meio da utilização de hormônios, ganha espaço na discussão jurídica no cenário nacional. Ocorre que, por ser uma técnica causadora de diversos efeitos colaterais, seu uso é questionável.

Outros tratamentos médicos, como o acompanhamento psicológico, podem se tornar uma opção, embora sejam pouco eficientes no que tangem ao desvio do comportamento do pedófilo.

Nesse contexto, serão explorados os seguintes questionamentos: O que é pedofilia? Esta deve ser vista como uma doença? Quem é o pedófilo? Quais os tratamentos médicos passíveis de aplicação ao pedófilo, como meio de reduzir seus impulsos sexuais? É possível elencá-lo como um inimputável? A castração química seria um mecanismo digno de prevenção a esse tipo de conduta? Esse tratamento viola direitos mais básicos do pedófilo?

Para responder a estas indagações, a metodologia compreenderá, por meio da revisão narrativa, o levantamento bibliográfico, que consiste em analisar, critico e meticulosamente, o que já foi produzido e registrado acerca do assunto em obras doutrinárias, periódicos, legislação, reportagens e documentos eletrônicos.

\section{DOS ASPECTOS CONCEITUAIS E JURÍDICOS DA PEDOFILIA}

Para Michel Foucault, os dispositivos histórico-culturais guiados pelo saber e pelo poder dominante, como "[...] a estimulação dos corpos, a intensificação dos prazeres, a incitação ao discurso, à formação dos conhecimentos, o reforço dos controles e das resistências" (FOUCAULT, 1997, p. 100), disciplinam as expectativas e as exigências sociais acerca do que se concebe, superficial e totalitariamente, como sexualidade.

Trata-se do poder disciplinar foucaultiano, que se traduz no domínio da administração da vida social, isto é, considera o corpo humano como uma máquina capaz de ser adestrada e transformada em um instrumento útil aos interesses políticos e econômicos. Esse poder recorre à tecnologia disciplinar do corpo por meio da "[...] punição e [da] vigilância como principais mecanismos para adestrar e docilizar o sujeito, pois é a partir deles que o homem se adequará às normas estabelecidas nas instituições" (DINIZ, 2014, p. 149-150), revelando-se como uma construção histórica e social sobre os modos de sentir e experimentar o corpo, os desejos e as relações (CASSAL, 2011, p. 466).

Ao ser cristalizada em padrões heteronormativos, a sexualidade humana se torna um tabu. Todas as condutas que fogem do que é encarado como normal, ganham contornos patológicos, os quais na maioria das vezes são coibidos, reprimidos e punidos para aquém de suas necessidades. É o caso das parafilias, como a pedofilia, que no sistema criminal brasileiro é encarada como um crime sem sequer ser explorada enquanto uma 
patologia. Para além de ser qualificada ou não como uma doença, em um primeiro momento, será apresentada suas características e definições.

Nessa perspectiva, a terminologia "pedofilia" ou paidophilia, conforme sua origem grega, advém da aglutinação das palavras paidós (criança) e filia (amizade, amor). Embora suas raízes etimológicas a indiquem como um ato de amor pelas crianças, sua conceituação, hoje, revestiu-se com um viés erótico e danoso aos infantes (MOREIRA, 2010, p. 99).

De acordo com a Classificação Internacional das Doenças (CID-10), a pedofilia é um distúrbio psiquiátrico elencado - assim como o fetichismo, o travestismo fetichista, o exibicionismo, o voyeurismo e o sadomasoquismo - como um transtorno de preferência sexual, de personalidade e de comportamento em adultos (ORGANIZAÇÃO MUNDIAL DA SAÚDE).

Do mesmo modo, o Manual Diagnóstico e Estatístico dos Transtornos Mentais V (DSM-V), caracteriza-a como uma parafilia manifestada por meio de comportamentos, fantasias ou impulsos sexuais intensos e recorrentes, envolvendo a atividade sexual com uma criança, em geral, com até 12 anos. Para tanto, indica que o pedófilo precisa ter, no mínimo, 16 anos de idade e que seja, pelo menos, cinco anos mais velho do que a vítima (AMERICAN PSYCHIATRIC).

Mathew Huss leciona, sob a ótica da Psicologia, que a pedofilia é considerada uma doença mental, tendo em vista que esta faz com que seu portador sinta atração sexual por crianças ou adolescentes, não se tratando de uma mera vontade. Nessa perspectiva, deve-se dissocia-la da concepção de crime e/ou de punição, já que se trata, na realidade, de uma condição mental cabível de tratamento médico contínuo (2011, p. 143).

Segundo Sônia Lyra, o desejo sexual de uma pessoa é uma ânsia dirigida para determinado fim, podendo ser simultaneamente um impulso natural bom e mal. Com isso, é possível afirmar que um sujeito pode ser portador dessa patologia sexual e nunca a manifestar ou sequer ser diagnosticado com tal durante sua vida, mesmo estando em contato com crianças (LYRA, 2010). Nessa concepção, o estímulo ao abuso sexual infantil acaba advindo de múltiplos fatores diferentes, como o meio em que o autor viva, o consumo de drogas, o estresse, dentre outros.

Sigmund Freud sustenta que conduta pedofilica pode ser dividida em duas categorias, quais sejam: a chamada pedofilia estruturada, em que a pessoa é pedófila por um desvio de sua sexualidade, atribuindo à figura da criança e do adolescente a atração afetiva e a sexual; e a denominada pedofilia oportuna, que é aquela em que o agente reveste os menores como um objeto sexual em potencial, aproveitando-se do acaso para cometer atos libidinosos (FREUD, 1905).

Para a psiquiatria, a pedofilia é categorizada como uma espécie de transtorno sexual que age como uma disfunção "do instituto sexual, fantasias ou comportamentos recorrentes e intensos que ocorrem de forma 
inabitual, também chamados de parafilias". Essa manifestação pode se dar como "sintoma de uma perturbação psíquica, como intervenção de fatores orgânicos glandulares e simplesmente como questão da referência sexual" (FRANÇA, 2013, p. 245).

Compreende-se pela expressão "parafilia" qualquer doença que intrinsecamente depende da substituição da atitude sexual convencional por qualquer outro tipo de expressão sexual desviante/inadequado, sendo este substitutivo a preferida ou única maneira da pessoa conseguir se excitar. Uma delas é a pedofilia, em que a inadequação se assenta na escolha do infante como objeto de satisfação sexual, como também na condição de risco em que a submete.

Em alguns indivíduos essas preferências ocorrem episodicamente, sendo que em determinados momentos ou até na maioria deles, o sujeito é capaz de exercer sua sexualidade normalmente, sem fantasias ou estímulos parafílicos.

A prática pedofilica pode ser denominada, nos dizeres de Viviane Guerra, como:

[...] o envolvimento de crianças e adolescentes, dependentes e imaturos quanto ao seu desenvolvimento, em atividades sexuais que não têm condições de compreender plenamente e para as quais são incapazes de dar o consentimento informado ou que violam as regras sociais e os papéis familiares. Incluem a pedofilia, os abusos sexuais violentos e o incesto, sendo que os estudos sobre a frequência sexual violenta são mais raros do que os que envolvem violência física (GUERRA, 1998, p. 3).

Por outro lado, Genival Veloso França parte para a análise da pedofilia como uma perversão sexual, caracterizada como a predileção erótica por crianças, denotando graves comprometimentos principalmente de cunho moral dos seus autores (2013, p. 247). A importância em classificar essa conduta como uma doença mental ou não reside na questão da imputabilidade penal do pedófilo, já que, se essa condição sexual for definida como uma doença mental, o agente causador pode ser considerado inimputável, refletindo em sua intervenção judicial.

Ocorre que, para o ordenamento jurídico brasileiro, não há a tipificação da conduta de pedofilia, isto é, não há na legislação brasileira o crime de pedofilia, somente há previsão quanto aos abusos sexuais dirigidos à criança, que segundo a Lei n. 8.069 de 13 de julho de 1990, também conhecida como Estatuto da Criança e do Adolescente (ECA), em seu artigo $2^{\circ}$, é aquela "pessoa até doze anos de idade incompletos", ou contra o adolescente, que é "aquele entre doze e dezoito anos de idade".

Alguns atos sexuais cometidos perante esse público estão tipificados pela Lei n. 12.015, de 7 de agosto de 2009, no capítulo dos Crimes Contra a Dignidade Sexual, mas é no ECA que se encontram normas penais direcionadas à proteção da criança e do adolescente em situações de abuso sexual.

Nesse sentido, o ECA, em seus arts. 240 e 241, dispõe que são crimes a violência, a exploração, o abuso, a opressão, a divulgação de imagens e vídeos envolvendo crianças ou adolescentes. Da mesma forma, o Código Penal, em seus arts. 217-A, 218, 218-A e 218-B, tipifica a conduta de induzir adolescentes menores de 14 a 
satisfazer a lascívia de outrem ou de expô-los ou induzi-lo à prática de conjunção carnal e demais atos libidinosos, como também de submeter alguém menor de 18 anos à prostituição ou a outra forma de exploração sexual.

Com o exposto, verifica-se que a pedofilia, a partir dos aspectos das ciências médicas, é uma doença parafilica de transtorno de perfil sexual, razão pela qual, é necessário o estudo de seu efetivo tratamento para ser aplicado, através do Direito, a intervenção jurídica mais adequada e digna ao abusador.

\section{DO PERFIL E DA (IN)IMPUTABILIDADE PENAL DO PEDÓFILO}

Ao contrário do senso comum, o perfil do pedófilo foge de qualquer estereótipo, nem sempre se enquadrando na figura socialmente construída de alguém "[...] aversivo e repulsivo, capaz de despertar sentimentos de asco, frequentemente associado com personagens do tipo marginal, vadios, desocupados, 'sujos', escroques ou solitários" (TRINDADE, 2007, p. 22).

Esses sujeitos são, geralmente, pessoas comuns do cotidiano da vítima, como os integrantes ou alguém relacionado à entidade familiar: o pai, a mãe, o padrasto, a madrasta, os tios, os avós e os vizinhos, isto é, aqueles próximos ao infante e que acabam passando despercebidos pela sociedade. Nesse sentido, o pedófilo não tem características físicas que o difere de outro indivíduo. Seu perfil é complexo e distante de ser um consenso, tendo em vista que qualquer classificação estará longe de refletir os múltiplos elementos que compõem sua personalidade.

Quanto ao instituto da imputabilidade penal, segundo Guilherme Nucci, é "o conjunto de condições pessoais que dão ao agente a capacidade para lhe ser juridicamente imputada a prática de um fato punível" (2010, p. 279). Trata-se de um elemento integrante da culpabilidade, o qual tem como fundamento a capacidade de entendimento do agente infrator sobre a ilicitude de sua conduta, como também de sua autodeterminação em prosseguir com o ato ou não (PRADO, 2013, p. 37-41).

A partir da análise do posicionamento médico sobre a pedofilia, Lillian Ponchio et. al defende que:

O pedófilo não comete o crime "por safadeza" (como se costuma ouvir normalmente). Muitas vezes o pedófilo não procura tratamento assim que percebe que está tendo fantasias sexuais envolvendo crianças e depois não consegue se controlar (2013, p. 49).

Nesse sentido, o mero fato do pedófilo ser portador de doença mental, se assim for caracterizado, não é o suficiente para qualificá-lo como inimputável. Para que isso ocorra, é preciso estar presente os critérios biopsicológicos, que são constituídos, como defende Damásio de Jesus, a partir de dois elementos normativos relacionados ao caráter ilícito do ato, quais sejam: o intelectivo, que é a condição do enfermo mental ter a capacidade de compreensão quanto à ilicitude de sua conduta e o volitivo, que é sua capacidade de autodeterminação, isto é, de controlar a sua vontade. Para o autor, basta a ausência de um desses dois itens para a ocorrência da inimputabilidade (2008, p. 503). 
Para se constatar a falta desses elementos, é indispensável à confecção de um laudo médico, com o objetivo de esclarecer, por meio de parâmetros técnico-científicos, a doença mental do agente abusador. Nesse quesito, Nelson Hungria e René Ariel Dotti relatam que o reconhecimento da causa biológica é tarefa do perito psiquiátrico, que deve, igualmente, dizer da influência dela na capacidade de discernimento ou poder de vontade do agente, ao tempo do fato criminoso (2016, p. 341-343).

$\mathrm{O}$ ordenamento jurídico brasileiro prevê determinadas possibilidades expressas em que ocorre a exclusão da imputabilidade, como a doença mental e o desenvolvimento mental incompleto ou retardado, que representam as causas biológicas capazes de acarretar na irresponsabilidade penal. Conforme o caput do art. 26 do Código Penal é isento de pena o agente que, "por doença mental ou desenvolvimento mental incompleto ou retardado, era, ao tempo da ação ou da omissão, inteiramente incapaz de entender o caráter ilícito do fato ou de determinar-se de acordo com esse entendimento".

Assim, para se aplicar a intervenção jurídica mais adequada ao pedófilo é fundamental a elaboração de perícia médica que conste sua capacidade de compreensão de sua conduta, enquanto ilícita, bem como, de seu autocontrole, enquanto exposto a situações que desencadeiam a manifestação de sua enfermidade. Caso seja constatada sua incapacidade parcial ou total do autocontrole sobre seus atos, o pedófilo deverá ser elencado como inimputável, merecendo tratamento penal para além da aplicação de uma pena. Destaca-se a medida de segurança, que visa prevenir e afastar, por tempo indeterminado, o inimputável revestido de periculosidade da vivência social.

De modo geral, são considerados como inimputáveis aqueles indivíduos que não tem pleno entendimento da ilicitude de seus atos, como também os que não são capazes de se autodeterminar quanto às suas ações, especialmente diante da manifestação de sua enfermidade. Este último elemento é ausente no pedófilo. O fator de periculosidade pode ser observado de acordo com o caso concreto ou, ainda, presumido pelo juiz nos casos estabelecidos em lei, dispensando, neste último caso, a avaliação de seu perigo.

Em se tratando das espécies de medida de segurança, estas podem ocorrer por meio da internação em hospital de custódia, de tratamento psiquiátrico, ambulatorial ou, na falta destes, em estabelecimento adequado, em conformidade com o art. 97 do Código Penal. Apesar do art. 26 desse mesmo Codex apresentar a isenção de pena ao inimputável que comete fato típico e antijurídico, a sentença absolutória desse sujeito é denominada como imprópria, tendo em vista que é aplicada uma medida de segurança.

\section{DA INTERVENÇÃO ESTATAL DIGNA E EFICAZ AO PEDÓFILO}

Após diversas notícias de casos de abusos cometidos contra crianças e adolescentes, intensificou-se no Brasil e no mundo a busca pela agravação das penas aplicadas aos delitos relacionados à liberdade e à 
incolumidade sexual.

Nesse sentido, Renato Silveira aponta que:

Inicia-se, assim, nos anos 90, um pontuar claramente punitivo e incapacitante, reclamando por uma aplicação de medida de segurança posterior à própria aplicação da pena, em uma versão do sistema do duplo binário. Esse sistema justifica um completo redesenhar de medidas complementares, sempre tendo em vista o asseguramento de que o condenado não venha novamente a delinquir. Nesse mesmo caminho, são encontradas situações temporais e outras perpétuas, a serem aplicadas depois da libertação, como é o caso de tratamentos hormonais - também chamados de castração química - e de registro pública (sic) de criminosos sexuais (2008, p. 286-287).

A possibilidade de tratamento médico do pedófilo, especificamente no que se refere a sua eficácia, ainda é um tema controvertido tanto para as ciências jurídicas quanto as médicas. No entanto, é dever do Estado agir em conformidade com o princípio da dignidade da pessoa humana, visando aplicar a intervenção jurídica mais apropriada a este indivíduo, seja por meio de uma pena, seja por uma medida de segurança. É essencial explorar, dessa forma, a efetividade da castração química enquanto pena, com a finalidade de se evidenciar o (in)cabimento da adoção dessa medida punitiva pelo ordenamento jurídico brasileiro, tendo em vista que o seu conflito com princípios e garantias constitucionais e infraconstitucionais distancia sua utilização da real finalidade de ressocialização do apenado.

Assim, para se analisar qual a intervenção mais digna e efetiva perante esse tipo de conduta, em um primeiro momento, será delimitado o que se concebe como dignidade humana e, posteriormente, o tratamento adequado e justo para o pedófilo, conforme suas peculiaridades de saúde mental. Observa-se que a figura da dignidade, em linhas gerais, pode ser entendida como um princípio e como um valor inerente à pessoa, isto é, que faz parte da personalidade do ser humano, não podendo ser suprimida. Ela possui muitos significados, o que dificulta uma definição exata, o que, porém, não esvazia seu conteúdo ou sua importância (SARLET, 2005, p. 18).

Enquanto princípio, sua observação é mandamental em todas as relações da pessoa, seja com o Estado ou com particulares. Enquanto valor, a dignidade será reconhecida, respeitada e protegida dentro da visão cultural e temporal de cada pessoa e sociedade. Para Immanuel Kant, o fato do ser humano ser racional é o que the torna merecedor de dignidade e respeito, soma-se a isto a sua autonomia e a sua capacidade de agir, que é, para ele, o que define a diferença entre a pessoa e os objetos (2007, p. 67).

Michael Sandel traduz, em poucas linhas e de forma excepcional, o pensamento de Kant a respeito da capacidade de raciocínio e de liberdade:

[...] nossa capacidade de raciocinar está intimamente ligada à nossa capacidade de sermos livres. Juntas, essas capacidades nos tornam únicos e nos distinguem da existência meramente animal. Ela nos transforma em algo mais do que meras criaturas com apetites (2011, p. 140).

A dignidade humana está inserida em uma categoria axiológica aberta, não podendo ter um conceito único e fixo, pois em verdade, ela está em permanente processo de construção e desenvolvimento, devendo ser 
constantemente concretizada, protegida e delimitada constitucionalmente (SARLET, 2005, p. 20-27).

Nesse sentido, Ingo Wolfgang Sarlet (2005, p. 30) e Fernanda Borghetti Cantali (2009, p. 155) convergem seus posicionamentos para tratar da dimensão dúplice desse princípio, de modo que, ao mesmo tempo em que protege a autonomia da pessoa, de se autodeterminar em relação às decisões acerca de sua existência (dimensão prestacional), também impõe ao Estado e à comunidade o dever de proteger a dignidade humana, incluindo sua abstenção em causar lesões (dimensão negativa). Por este entendimento, é certo que o Estado e a sociedade, no cumprimento da dimensão prestacional da dignidade em relação a um indivíduo portador de uma doença, devem protegê-lo, inclusive de seus próprios atos contra terceiros, com base no direito à vida, à saúde, à integridade física e psicológica, entre outros.

Pietro Alarcón apresenta uma visão valorativa da dignidade humana. Para o autor, não se pode tratá-la apenas como um princípio, mas como um valor constitucional:

Transcende, assim, a dignidade consignada no art. $1^{\mathrm{o}}$, inciso III da Constituição, o normativismo puro e simples, outorgando um status que para muitos permanece inadvertido, mas que, no entanto, é determinante para a persistência da forma de Estado, o de membro da coletividade, o de participar da humanidade, de ser uma partícula viva, arte e parte do gênero humano (2004, p. 251).

A dignidade humana, seja como valor axiológico ou princípio basilar de um ordenamento jurídico, deve reconhecer o ser humano como o seu destinatário único e final, independentemente de sexo, raça, religião, condição física, sexual e/ou mental. Neste sentido, todo sistema jurídico e administrativo do Estado deve trabalhar para o máximo desenvolvimento de todas as pessoas, sem preconceitos, incluindo aqueles que são acometidos com a parafilia pedofilica.

Para Christiane Sanderson, a pedofilia, por ser um transtorno mental crônica, isto é, uma doença que carece de cura, é passível de tratamento e acompanhamento médico que deverão ser contínuos. Mais do que isso, a autora defende um tratamento digno (2005, p. 34). Por outro lado, Trindade alerta que essa intervenção médica, em específico a psicológica, geralmente é muito difícil de ser efetuado, uma vez que:

Em geral, eles [os pedófilos] recorrem à mentira e ao ludibrio. Carecem de empatia e de cooperatividade. Seus interesses costumam ser limitados. Como regra, não apresentam sentimento de culpa e são egossintônicos, faltando-lhes aquele desconforto emocional interior necessário para a mudança. Não possuem motivação. São sedutores e envolventes e transportam esse tipo de funcionamento para a relação terapêutica. Além disso interrompem o tratamento tão logo alcançam algum benefício secundário. Essas características são responsáveis pelo ceticismo dominante quando se cuida de tratamento psicológico (2007, p. $35)$.

Diante dessa dificuldade, bem como do sensacionalismo que se criou em torno dessa temática, muitos doutrinadores e operadores do Direito passaram a defender, equivocadamente, a ideia de castração química como uma solução, especialmente com um viés de punição.

Desde a Antiguidade, a castração é utilizada como um método de castigar aquele que cometia alguma 
infração ligada às questões sexuais. A Lei de Talião, conhecida popularmente por exprimir o ditado "olho por olho, dente por dente", era comumente recorrida para esse assunto, resultando em condenações proporcionais ao dano causado, como a de esmagamento das genitálias e a submissão do corpo do condenado a torturas, visando romper e/ou lesionar os tecidos de seus órgãos reprodutivos (BUBENECK, 2007, p. 15).

Archimedes Marques (2010) relata que a técnica mais comum era a capação, a qual consistia em posicionar a bolsa escrotal do infrator em um local rígido para ser esmagada por golpes de bastão confeccionado com madeira de lei. Hodiernamente, com o advento dos tratados internacionais de proteção aos direitos humanos, bem como o reconhecimento dos direitos fundamentais, os métodos cruéis e considerados desumanos como forma de punição foram abolidos, passando a elencar a dignidade humana como parâmetro da atuação estatal.

Nesse sentido, a castração química, como instrumento de controle da doença pedofílica, deve ser analisada para se verificar se é uma alternativa que viola seus direitos. Foi nos Estados Unidos da América, na década de 90, que essa intervenção médica ganhou destaca, consistindo na aplicação de hormônios que inibem o desejo sexual. O estado americano da Califórnia foi o primeiro a adotá-la, espalhando-se aos Estados da Geórgia, Montana, Oregon e Wisconsin (CABRAL, 2016). Para tanto, essa medida é, segundo Pedro Ferreira:

[...] um tratamento terapêutico temporal e completamente reversível mediante o qual se injeta no homem um hormônio sintético feminino - Depoprovera (acetato de medroxiprogesterona/DMPA) - que produz um efeito antiandrógeno que reduz o nível de testosterona para inibir o desejo sexual durante, aproximadamente, seis meses (FERREIRA, 2009).

Dessa forma, a castração química, também denominada como hormonal, é um tratamento químico temporal, em que sua dosagem varia de paciente para paciente. Apesar de ser um procedimento reversível, seus efeitos colaterais permanecem como o cerne das controvérsias acerca de sua utilização, tendo em vista que a castração medicamentosa pode resultar, em longo prazo, em enfermidades cardiovasculares, osteoporose, depressão, dores de cabeça, trombose etc (PONTELI, 2010).

Mais do que o controle da libido do abusador, os efeitos da castração química, de igual modo, afetam e degradam o físico/biológico daquele que a receber, razão pela qual não é possível afirmar que esse tratamento é isento de riscos. A principal crítica para a sua não utilização se refere à violação aos princípios da inviolabilidade da vida e da integridade física, bem como da autonomia do indivíduo que é exposto a esse procedimento.

O princípio da inviolabilidade está previsto art. 5o, caput da CF, em conformidade com Michael Kloepfer, "Ele abrange a existência corporal, a existência biológica e física, que é pressuposto vital para a utilização de todos os direitos fundamentais. A proteção refere-se, aqui, a vida individual, não apenas à vida humana em geral" (2009, p. 150).

Diante desse descumprimento de princípios bioéticos e constitucionais, é importante analisar a castração 
sob o viés de penas cruéis, as quais Archimedes Marques defende que:

Apesar do nosso ordenamento jurídico ter abolido de vez as penas cruéis, a discussão sobre a aplicação de uma pena peculiar para aqueles que cometem crimes de ordem sexual, destarte para aqueles praticados contra crianças através da chamada pedofilia, volta a tona agora de maneira mais presente, vez que tramita no Congresso nacional o Projeto de Lei no 552/07 de autoria do Senador Gerson Camata para propor modificação no Código Penal com a pena de castração através da utilização dos recursos químicos, ou seja, a castração química para tais criminosos (2010).

No artigo 5o, inciso XLIX, a CF/88 é assegurado "aos presos o respeito à integridade física e moral", impossibilitando toda medida exploratória de direitos aos detidos por parte do Estado. Ainda, no art. 5º no seu inciso X, do Texto Maior, é ressaltada a inviolabilidade da intimidade, da vida privada, da honra e da imagem.

Da mesma forma, o art. 38 do Código Penal dispõe que "O preso conserva todos os direitos não atingidos pela perda da liberdade, impondo-se a todas as autoridades o respeito à sua integridade física e moral", como também, a Lei de Execuções Penais impõe como limite das penas "o respeito à integridade física e moral dos condenados e dos presos provisórios".

O Pacto San José da Costa Rica, em seu art. $5^{\circ}$, preceitua que ninguém deverá "ser submetido a torturas, nem a penas ou tratos cruéis, desumanos ou degradantes", em que "toda pessoa privada da liberdade deve ser tratada com respeito devido à dignidade inerente ao ser humano".

Embora a Constituição Federal e os tratados internacionais dos quais o Brasil é signatário tenham abolido qualquer penalidade degradante e cruel, a castração química, que é um procedimento invasivo à saúde e violador de diversos direitos do pedófilio, ainda é vista como uma possibilidade de controle dessa doença. $\mathrm{O}$ Poder Público deve não somente se abster de cometer atos que atentem contra a dignidade desse indivíduo, mas também agir positivamente, como forma de garantir o mínimo existencial a cada ser humano.

A castração química se reveste, em conformidade com o exposto, como uma pena degradante, tendo em vista que, segundo Pedro Pereira, "priva de dignidades, torna vil, estraga, deteriora aquele que é submetido a ela. É ainda cruel, pois desumana, dolorosa, prejudica enormemente a vida daquele que a receba como parte da reprimenda" (PEREIRA, 2016). Nessa perspectiva, condenar alguém a esse processo é, no mínimo, desrespeitar os direitos mais imanentes do ser humano, como à vida, à liberdade e a integridade física e psíquica, já que ninguém tem o poder deles dispor, mesmo que para o seu próprio benefício.

\section{CONCLUSÃO}

Conclui-se que, pelo viés das ciências médicas, é possível caracterizar a pedofilia tanto como um distúrbio psiquiátrico de personalidade e de comportamento em adultos, quanto uma parafilia pedofilica. Em ambos os casos, trata-se de uma doença mental que acomete o pedófilo. Em virtude de ser uma conduta praticada geralmente no seio intrafamiliar, verifica-se que tal é de difícil detecção, já que o perfil do pedófilo se distancia do 
estereótipo preestabelecido do senso comum.

Por se revestir como uma enfermidade, a pedofilia não suprime a capacidade de entendimento do pedófilo, mas afeta a autoderminação de seus atos e, em decorrência disso, bem como por não ser passível de cura, ele deve ser considerado como inimputável.

Constatou-se, ainda, que, embora muitas pessoas possuam tendências à pedofilia, grande parte não praticará ilícitos de caráter sexual, justamente por possuírem autocontrole sob sua parafilia, razão pela qual o Poder Público deve, por meio de exames médicos e psicológicos, considerar o poder limitado do pedófilo frente seus impulsos ao desejo sexual infantil, intervindo penalmente de modo coerente à dignidade do pedófilo.

Não se nega a essencialidade do Estado em buscar a ressocialização do agente abusador, nem mesmo as consequências devastadoras e, na maioria das vezes, irreversíveis causadas às suas vítimas. Ocorre que, acima de qualquer punição, deve ser considerada a finalidade da intervenção estatal, que é ressocializar, de modo efetivo e digno, aquele que cometeu algum ilícito, especialmente se este for portador de um transtorno mental.

Por óbvio, a mera privação de liberdade em um sistema carcerário do agente causador não irá resolver ou tratar o problema central, que não está pautado apenas na vontade em materializar o crime, mas, sim, em resgatálo ao sadio convívio social, demonstrando-se uma intervenção ineficiente e indigna ao perfil desse doente. Nessa perspectiva, a medida de segurança em detrimento da pena se evidencia o instrumento mais coerente e indicado, devendo o magistrado aplicá-la em conformidade com as necessidades e peculiaridades médicas do pedófilo.

Por fim, a castração química, como medida punitiva, por ocasionar diversos efeitos lesivos à saúde do agente causador ao abuso sexual infantil, está distante de respeitar dignidade deste, tendo em vista que viola princípios e garantias constitucionais e da bioética, como o direito à vida, à integridade física, como também ao princípio da autonomia da vontade.

\title{
THE JURIDICAL ASPECTS OF PEDOPHILIA: TOWARDS A DIGNIFIED AND EFFECTIVE STATE INTERVENTION FOR THE PEDOPHILE
}

\begin{abstract}
Pedophilia is a controversial issue both in the legal and social spheres. The discussion of whether the pedophile as a sick person or not, is still far from reaching a consensus, reflecting directly on a due state intervention on the subject. Therefore, this research aimed at analyzing, through bibliographic survey, the conceptual and juridical aspects of pedophilia. For this, the profile of the pedophile was explored, pointing out, from the medical perspective, as a carrier of mental pathology, that is, of a paraphilia. Furthermore, we show such individual as unable of being charged, fir he/she is deprived of the capacity for self-determination of his /her deeds. Thus, a dignified and effective state intervention was analyzed in addition to the application of a sentence and prescribing security measure as the most humane outcome.
\end{abstract}


Keywords: Chemical Castration; Personality Rights; Security measure; Pedophilia; Pedophile.

\section{REFERENCIAS}

ALARCÓN, Pietro de Jesús Lora. Patrimônio Genético Humano e sua proteção na Constituição Federal de 1988. São Paulo: Método, 2004.

AMERICAN PSYCHIATRIC ASSOCIATION (APA). DSM-5: Manual diagnóstico e estatístico de transtornos mentais. Tradução de Maria Inês Corrêa Nascimento et. al. 5. ed. Porto Alegre: Artmed, 2014.

BASSO, Maristela. Curso de direito internacional privado. São Paulo: Atlas, 2009.

BUBENECK, Celso. Sobre penas de morte: subsídios históricos e jurídicos. Prática Jurídica, Brasília, ano VI, n. 60, 31 de março de 2007.

CABRAL, Bruno Fontenele. Discussão sobre a constitucionalidade da castração química de criminosos sexuais no Direito Norte-Americano. Disponível em: <http://jusvi.com/artigos/43525>. Acesso em: 30 mai. 2016.

CANTALI, Fernanda Borghetti. Direitos da personalidade: disponibilidade relativa, autonomia privada e dignidade humana. Porto Alegre: Livraria do Advogado, 2009.

CASSAL, Luan Carpes Barros; GARCIA, Aline Monteiro; BICALHO, Pedro Paulo Gastalho de. Psicologia e o dispositivo da sexualidade: biopolítica, identidades e processos de criminalização. Revista Psico. v. 42, n. 4, p. 465 473, out./dez. 2011. Disponível em:

<revistaseletronicas.pucrs.br/fo/ojs/index.php/revistapsico/article/view/8600>. Acesso em: 14 fev. 2017.

DINIZ, Francisco Rômulo Alvez. OLIVEIRA, Almeida Alves de. Foucault: do poder disciplinar ao biopoder.

Revista Scientia. v. 2, n. 3, p. 143 - 158, jun.2014. Disponível em:

<www.faculdade.flucianofeijao.com.br/site_novo/scientia/servico/pdfs/VOL2_N3/FRANCISCOROMULO ALVESDINIZ.pdf $>$. Acesso em: 14 fev. $20 \overline{17}$.

DUNAIGRE, Patrice. O ato Pedófilo na História da Sexualidade Humana. In UNESCO. Inocência em perigo: abuso sexual de crianças, pornografia infantil e pedofilia na internet. Rio de Janeiro: Garamond, 1999.

FERREIRA, Pedro Paulo da Cunha. A castração química como alternativa no combate à pedofilia; algumas palavras acerca do Projeto de Lei n. 552/2007 e o modelo político-criminal emergencial. Ciências Sociais Aplicadas em Revista, Marechal Cândido Rondon, v. 9, n. 17, 2009.

FOUCAULT, Michel. A história da sexualidade 1: a vontade de saber. 12. ed. Trad. Maria Thereza da Costa Albuquerque e J.A. Guilhon Albuquerque. Rio de Janeiro: Graal, 1997.

FRANÇA, Genival Veloso de. Medicina legal. 9. ed. Rio de Janeiro: Guanabara Koogan, 2013.

FREUD, Sigmund. Três ensaios sobre a teoria da sexualidade. Rio de Janeiro: Imago, 1905, v. 7. 
GRANDE DICIONÁRIO HOUAISS BETA DA LÍNGUA PORTUGUESA. Verbete: pedofilia. Disponível em: <http://houaiss.uol.com.br/busca.jhtm?verbete=pedofilia\&stype=k $>$. Acesso em: 23 jul. 2016.

GUERRA, Viviane Nogueira de Azevedo. Violência de pais contra filhos: a tragédia revisitada. 3. ed. São Paulo: Cortez, 1998.

HEIDE, Márcio Pecego. Castração química para autores de crimes sexuais e o caso brasileiro. Jus Navigandi, Teresina, ano 11, n. 1400, 2 maio 2007. Disponível em: <http://jus2.uol.com.br/doutrina/texto.asp?id=9823>. Acesso em: 30 mai. 2016.

HUNGRIA, Nélson; DOTTI, René Ariel. Comentários ao Código Penal. 7. ed. Rio de Janeiro: Gz, 2016, Tomo 2, v. 1.

HUSS, Mathew T. Psicologia Forense: pesquisa, pratica clínica e aplicações. Porto Alegre: Artmed, 2011.

JESUS, Damásio E. Direito Penal: Parte Geral. v. 1., 29. ed. São Paulo: Saraiva, 2008.

KANT, Immanuel. Fundamentação da Metafísica dos Costumes (Tradução Paulo Quintela). Lisboa: Edições 70, 2007.

KAPLAN, Haroldl. Compendio de psiquiatria: Ciências do Comportamento e Psiquiatria Clínica. 7. ed. Porto Alegre: Artes Médicas, 1997.

KLOEPFER, Michael. Vida e dignidade da pessoa humana. In.: SARLET, Ingo Wolfgang (org.). Dimensões da dignidade: ensaios de filosofia do direito e direito constitucional. 2. ed. Porto Alegre: Livraria do Advogado, 2006.

LIMA, Antõnio Henrique Maia. Pedofilia: concepções psicanalíticas sob uma perspectiva freudiana. 2014. Disponível em: <http://www.ambitojuridico.com.br/site/?n_link=revista_artigos_leitura\&artigo_id=13554 \&revista_caderno=3>. Acesso em: 10 jul. 2016.

LYRA, Sonia Regina. Pedofilia- O Fascínio do horror. Jornal Universidade, n. 127, abr. 2010. Disponível em: <http://www.ichthysinstituto.com.br/artigos_detalhe.asp?ID=51>. Acesso em: 15 de mai. 2016.

MARQUES, Archimedes. Crimes sexuais: da antiga capação para a moderna castração química. 2010. Disponível em: http:/ /www.artigonal.com/advertising-artigos/crimes-sexuais-da-antiga-capacao-para-a-moderna-castracaoquimica-2120188.html. Acesso em: 12 de mai. 2016.

MOREIRA, Ana Selma. Pedofilia aspectos jurídicos e sociais. Leme: Cronus, 2010.

NUCCI, Guilherme de Souza. Código Penal Comentado. 10. ed. São Paulo: Revista dos Tribunais, 2010.

ORGANIZAÇÃO MUNDIAL DA SAÚDE. Classificação Estatística Internacional de Doenças e Problemas

Relacionados à Saúde - CID-10. Disponível em: <http://www.cid-10.org/codigos/f65-4-pedofilia >. Acesso em: 12 jun. 2016.

PEREIRA, Pedro H. S. A castração química à luz dos princípios da proporcionalidade, dignidade, e vedação de penas cruéis. Disponível em: <http://jusvi.com/artigos/42258>. Acesso em: 30 jun. 2016. 
PICCIRILLO, Miguel Belinati; FARACO NETO, Pedro. Dignidade da pessoa humana: Fundamento da República Federativa do Brasil. In.: SIQUEIRA, Dirceu Pereira; AMARAL, Sérgio Tibiriçá (Org.). Democracia, Liberdade e Justiça: Fundamentos para uma Teoria Jurídica do Reconhecimento. Birigui: Boreal, 2015. Cap. XIV.

PONCHIO e SILVA, Lilian et. al. Pedofilia e abuso sexual de crianças e adolescentes. São Paulo: Saraiva, 2013.

PONTELI, Nathália Nunes; SANCHES JR, Carlos Alberto. Notas para uma análise sociológica da castração química. Revista LEVS, São Paulo, n.5, 2010. Disponível em:

$<$ http://www.levs.marilia.unesp.br/revistalevs/edicao5/Autores/nathalia_nunes-carlos_alberto.htm >. Acesso em: 14 jul. 2016.

PRADO, Luiz Regis. Curso de Direito Penal Brasileiro: parte geral, arts. 1 a 120. 11. ed. São Paulo: Revista dos Tribunais: 2013.v. 1.

SANDEL, Michael J.Justiça - o que é fazer a coisa certa. 4. ed. (Tradução de Heloisa Matias e Maria Alice Máximo). Rio de Janeiro: Civilização Brasileira, 2011.

SANDERSON, Christiane. Abuso Sexual em Crianças: Fortalecendo Pais e Professores Para Proteger Crianças de Abusos Sexuais. São Paulo: M. Books do Brasil, 2005.

SARLET, Ingo Wolfgang. As dimensões da dignidade da pessoa humana: construindo uma compreensão jurídico-constitucional necessária e possível. In.: SARLET, Ingo Wolfgan (Org.) Dimensões da dignidade Ensaios de Filosofia do Direito e Direito Constitucional. Porto Alegre: Livraria do Advogado, 2005.

SERAFIM, Antônio Pádua et al. Perfil psicológico e comportamental de agressores sexuais de crianças. Revista Psiquiatria Clínica, São Paulo, v. 36, n. 3, 2009. Disponível em: <www.revistas.usp.br/rpc/article/viewFile/17252/19265>. Acesso em: 15 de mai. 2016.

SILVEIRA, Renato de Mello Jorge. Crimes Sexuais: bases críticas para a reforma do direito penal sexual. São Paulo: Quartier Latin, 2008.

TRINDADE, Jorge; Aspectos psicológicos. In.: BREIER, Ricardo. Pedofilia aspectos psicológicos e penais. Porto Alegre: Livraria do Advogado, 2007.

Trabalho enviado em 19 de dezembro de 2016.

Aceito em 29 de junho de 2017. 